\title{
Analysis and Reflection on Motivation of Vocational College Student Association Development
}

\author{
Chunlan Zhang \\ Nanjing City Vocational College, Jiangsu, Nanjing, 210002, China
}

Keywords: Vocational college, Student association, Status, Motivation

\begin{abstract}
Student association is an irreplaceable part in higher vocational quality education, and it is a melting pot for students to improve their capabilities. Students association is organized by a group of students with common interests to facilitate self-management, self-development, and self-service. This paper will analyze the functions and features of student association for further research on the status and motivation of student association development, and ultimately propose constructive comments beneficial to development of vocational college student association.
\end{abstract}

\section{Functions and features of students association in vocational college}

College student association is organized by a group of students with common interests, goals and ideas, expertise and advantages, and they develop a set of management mode to maintain group order. In student association, students freely organize activities including aim of planning activities, form, time, place, significance and specific processes. College student associations are mostly flexible and free, have loose structure, self-discipline behavior, and far-reaching effect.

Based on this, understanding college student association development motivation, means internal and external factors to promote association development, such as association internal structure, management mode and reward system, financial support, association activities and venues, all of which are important factors affecting association development. Motivation is the basis of operation, and in order to develop a thriving association, we must start with makeup of development motivation, for which, the author will make an elaboration in the paper. Student association can improve students' organization and leadership ability, practical and innovative ability, and these outstanding members are leaders and main force in the construction of the campus culture. The establishment of different associations provides a large platform for fair competition, and friendly cooperation between students. The biggest feature of college student association is to enable members to dig more potential after completion of their work, so as to maximize existence meaning of each member and influence of association

\section{Status and existing problems of college student association development}

Association is a big stage for students' self-expression. Orderly and smooth development of association work is the driving force of association development, but obstacles still exist. The author will in detail analyze status and existing problems of college student association development from perspectives of association external and internal conditions in this section.

\section{External condition of association}

Association activities are not stable, and lack sustained vitality

At the beginning of the new school year, various associations will start to recruit, interview, open welcome party, and then association leader and vice-leader participate in various activities, which is the annual prosperity period of association development, and at this period, motivation, sense of presence of each member, and the realization of self-worth are also in peak state. But after less than two months, association activities will be finished in succession, the original thrive will be replaced by idleness of members who cannot find their sense of presence. Change of leaders in association becomes nothing but form because the person in charge is determined in advance, resulting in that participants no longer have sense of participation, and leaders manage nobody else, but just waiting 
for new leaders after the year, to complete the transfer of their task, again and again, so that association activities are not stable, and lack sustained vitality

Association activities are limited due to fund, place, and facilities and so on, resulting in undesired effect

Currently, fund resource of college student association activities is broadly divided into three categories: first, fund support from administrative expenses of Communist Youth League in school, but because of the large number of associations, the financial support is not too much; second, membership fee from each member, but the total is also very limited; third, to support most part of expense in association through sponsorship, and sponsorship forms are diversified, such as: advertising, lectures by social education persons, lectures for 4-level \& 6-level English, postgraduate exams, and study abroad, and social sponsors and other social units, but these sponsorship forms are unstable, so the association will always face the problem of lack of fund. And various activities carried out by association need funds, such as making certificates, advocacy, lectures, exhibitions, publications, social surveys or social practice, which makes association get stressed out. In addition, necessary facilities, equipment, place, and others required for activities need funding and certain enabled conditions. Lack of fund and enabled condition restrictions make association activities not be carried out properly, not achieve the desired effect planned in activities plan.

Association activities content are outmoded and formalism is serious

Student associations in most colleges will follow and carry out previous activities. These activities are repeated every year, and content and form will inevitably fall into the stereotypes. Senior students before participating such activities may lose interest, thus nearly three-quarters students will not participate. Also, a number of association activities focus only form but ignore the most important thing and the significance of activities. Superficial activities undoubtedly will make people lose their impressions and interest. They do not achieve the desired purpose of activities, but lower the presence sense of overall association in the school. Therefore, outmoded activities and formalism are also serious problems of student association.

\section{Association internal conditions}

\section{Imperfect management and unsound internal mechanism}

Only perfect internal management and sound mechanisms can contribute to healthy and stable development. A mature association always focuses on the interests of the collective, encourages students to actively participate in. Experienced seniors and leaders (or deputy) will give suggestion and guidance in thinking, organizational management, activities content, expertise, etc. to help newcomers to master social skills, establish correct sense of social responsibility in activities. While the immature association fails because its internal organization is immature, lacks management experience, and does not establish sound working mechanism. Further, association leaders in colleges will be changed every year, and many student associations do not develop strict rules and administrative procedures over the years, resulting in the loose internal management. Association members do not have clear attitude, and they think that as long as they pay the membership fee, they become a member, only to receive a the integrated test strip for final examination, and their existence has little significance for the association, so indifferent to association activities or development, thereby limiting the long-term and stable development of student associations.

Unbalanced association development and unsound incentive mechanism

Every year, recruiting new members and election of persons in charge will last for a long period, so that association activities in this period slow or even stall, resulting in unbalanced development. Association and members incentive mechanism is not perfect, and the election is essentially decided by persons in charge last year, resulting in that members do not have strong sense of competition and association does not form good competitive atmosphere inside, which also affects the balance of association development. Faced with this difficult situation, associations with larger scale, greater influence, and stronger cohesion and strength because of these obvious advantages can avoid disadvantages, and still continue development, but other common associations will meet various problems during activities, in addition to the imperfect incentive mechanism, the association cannot function properly. 
Association activities lack professional guidance and association features are difficult to be embodied

Association is set up by groups of students freely, so many colleges and universities don' $t$ provide full-time instructors to guide operation of association activities. In addition, recruiting professional instructors for guidance also requires a fixed remuneration, and this expenditure is a lot of pressure for many associations, so that instructor resource is not sufficient. Due to insufficient experience and consideration, when students organize activities by themselves, inevitably there will exist difficulties and obstacles, resulting in that association features are difficult to be embodied due to lack of professional guidance, which is also one of the dynamic factors affecting the development of the association.

\section{Motivation and constructive suggestion for association development}

\section{Suggestion on external conditions}

Recruit members according to their capabilities to make association development stable

Policy of student associations is not harsh, so college students can choose a proper association according to their interests and hobbies. What kind of society to join in, and what activities to participate in, are chosen by students freely, without affecting their professional learning. But for all associations, then cannot recruit each comer, without any selecting, but should consider to be responsible for the school, students, and long-term and stable development of the association. Recruiting new members according to their capabilities can keep continuous and stable development of student association, and enable each active member to shine themselves on the stage for self-development and self-show.

Leaders put more emphasis and increase support to ensure healthy development of association

In spiritual civilization construction of colleges, the most important part is the construction and development of student association. Colleges should pay much attention to the construction of student associations and give some certain support and encouragement. For example, give certain fund support and reward to outstanding associations, select outstanding associations, or associations making the most contribution and have the greatest influence, or give some credit and comprehensive measurement reward. They can set aside special funds from school fees at the beginning of school used as college student activities fund and financial support, and provide some venues, facilities and other hardware guarantee for activities. Of course, public relations department dedicated inside the association members should seek sponsorship, to get part of activities financial support. This will not only ease the plight of financial constraints, but also exercise the social practice of college students, master the social skills, broaden their horizons and also accumulate experience for employment during touch with people in all levels of society, but in seeking social sponsorship, it should be noted that sponsorship activities must be positive, and beneficial to physical and mental health of college students, and students try to contact with outstanding social elites. In short, schools and association leaders should explore correct and effective management styles and methods according to the actual situation, to ensure long-term and healthy development of the association.

Improve activity level and create good culture atmosphere

Association activity should be based on their own objectives, and reflect some spiritual needs the association advocates, such as competitive spirit, innovation spirit, scientific spirit, subject spirit, teamwork spirit, dedication, democratic spirit, service spirit and pioneering spirit, thereby improving activity level, reflect its own characteristics. To change the form and content of the activity, we should focus on content, innovation, and interests of association members, increase knowledge and meaning of activity, enable college students to increase their knowledge, acquire more cultural knowledge, create good culture atmosphere, and at the same time make association activities achieve the desired result and effect expected in planning book. 


\section{Suggestion on internal conditions}

\section{Adjust existing structure and organize management mechanism}

Colleges should build association education system meeting vocational education reform needs. With the establishment of various types of associations, construct Party, League Branches in the association, which will help to properly guide the healthy and sustainable development of associations. All associations should develop a set of rules and management system with viability and higher value as per requirement of upper-level management organization, strengthen implementation to further strengthen internal management. Each association shall use its own resources, strengthen publicity, increase public relations capacity, promote association image, and strengthen internal management and external coordination and supervision, to more orderly carry out association activities. In internal and external publicity, stick to be realistic, making association activities truly become brand activities, without falsifying. In addition, the nature and impact of association activities must comply with relevant state regulations, and the external management system has an important responsibility in terms of monitoring association development direction, and must ensure positive association activities, which contribute to healthy physical and mental development of college students. Student association activities can be appropriately incorporated into the credit system, namely students through formal procedures participate in association activities, combine with related courses, and students with outstanding performance in association activities can get credits. Adjust the existing structure, to make management mechanism meaning and objectives clearer.

Perfect incentive system and ensure balance development

Member management and promotion system should strictly avoid the internal decisions by previous persons in charge, and promotion should be based on students' ability and qualities to long-term ensure the quantity and quality of internal association members. Association shall strengthen the member management through various ways such as prizes and welfares, and this treatment needs support from school. School develops measures in terms of awarding and appraising, and those members who have made outstanding contributions to the development of association should enjoy the same treatment as student leaders. On the contrary, those who do not do their work well should be dismissed as soon as possible, in order to achieve the most efficient and optimized resource integration. If some members really need to leave due to personal reasons, they need to make form application in writing and obtain approval before leaving.

Fully exert the role of instructors and promote depth and breadth of association activities

Association management and operation still mostly depends on persons in charge. Arrange full-time instructor to guide the operation of association activities to improve the quality of association activities, enhance cohesion, appeal and influence of association organizations. Some counselors can also serve as full-time instructor and engage in association administration work. Schools should try to provide specialized instructor for each association with larger scale and influence. The instructor may be acted as counselor, retired teacher, or old teacher who has interest. Thus, the instructor can fully play its role in promoting the construction level, and guarantee quality grades of association. In addition, school should conduct association construction and performance appraisal, reward excellent associations and punish inferior ones.

\section{Conclusions}

In summary, college student association is an important front for effectively keeping young students together and carrying out ideological and political education, and an important stage for quality development. Student association has an important role for vocational colleges, the prosperity of the campus culture, promotion of campus culture construction, and also healthy growth of the students. Association development motivation is like the wheel axis, and rotation of the axis will drive the wheel to run. It is a key factor in association development. Therefore, only after we objectively analyze and reflect on the status and problems of vocational college student association development motivation, and make the corresponding constructive measures against these analysis, we can ensure long-term healthy and stable development of student association. 


\section{Acknowledgments}

This paper is Nanjing Vocational College School-level Funded Project Stage Achievement, Subject name: Research on Vocational College Student Association Development motivation and Leading Strategy, Number: KY201518.

\section{References}

[1] Ding Qiuyi. Current Situation and Countermeasures of Student Association Construction. Chongqing Normal .2011

[2] Pi Li. On Function of College Student Association. Journal of Hubei University of Economics. 2011 (09): 157-158

[3] Li Min. On Current College Student Association Management Problems and Countermeasures. Yanshan University. 2012

[4] Liu Wenga. Play Educational Function of Student Association Construction. Liaoning Vocational College Journal. 2012 (3): 109-110. 